\title{
Aggregate P Wave Duration
}

National Cancer Institute

\section{Source}

National Cancer Institute. Aggregate P Wave Duration. NCI Thesaurus. Code C117775.

An aggregate $\mathrm{P}$ wave duration value based on the measurement of $\mathrm{P}$ wave duration intervals from multiple beats within a sing le ECG. The method of aggregation, which can vary, is typically a measure of central tendency such as the mean. (CDISC) 